\title{
OBJECTIVES AND ORGANIZATION OF THE CARIES CONTROL WORKSHOP
}

\author{
Kenneth A. Easlick, A.M., D.D.S., Professor of Public Health Dentistry, \\ University of Michigan, Ann Arbor, Mich.
}

An alumnus of the University of Michigan* (and we here in Ann Arbor always are partial to the statements of graduates of the University of Michigan) stated recently that, to a considerable degree, the history of man is the history of myths. Myths, probably to most of you, suggest the folkways of primitive peoples and of ancient civilizations. I think that you will find, however (you will if you join the members of the Council on Dental Health in their evaluation of the dental health statements in school textbooks!), that many ancient myths still are believed and some new ones actually are being made. Some of these new ones appear to us on the Council on Dental Health as more detrimental to human welfare than the old ancient myths that are a half or a quarter believed.

And I should like to pursue this thought just a moment further. Myths flourish by repetition and the tradition of authority. I can point out a statement in one dental textbook which quoted an "authority" in its first edition and repeated him for five successive editions. The statement of the authority had been killed abruptly by a piece of laboratory researeh some years before the printing of the original textbook, the very first edition.

I told an unappreciative representative of a book-publishing company recently, when he annoyed me about writing a book, that textbooks make excellent mausoleums for burying dead knowledge and that I hoped the purchasers merely bought textbooks to fill up empty shelves and that it was a shame to disturb dead things because so many of them smell vilely. And I think that many of you may have had the same discouraging experience as have $I$; you have scanned a new text and found statements that were already out of date by the time it was published. Now, right here I think that I should pause, perhaps, and offer my apologies to any of you brave ladies and any of you courageous men in this auditorium who ever have written a textbook.

In passing, it may be worth while to note that myths also flourish by the coercive control of learned societies and distinguished groups. Then myths die hard, because it is difficult for scientific fact and common sense to demonstrate the myths' absurdity and harmfulness. They seldom die a real decent death when pompous individuals will to "believe" rather than to "conclude."

Any scientific hypothesis should survive when verified by fact and any unscientific hypothesis should die a clean-cut and final death when found invalid. It is hard to envision a true seientist who would try to preserve a poorly conceived hypothesis by burning people at a stake, putting them in concentration camps or even branding them as un-American. The true scientist forgets his "preliminary reports" and his once intriguing hypothesis and goes to work on

*Bain, Read. Man, the Myth-Maker. Scientific Mo., 65: 61-9, July, 1947. 
something new and more productive. And, Ladies and Gentlemen, it is something of this point of view which I have hoped can be interjected into this week's work.

Time after time, when our dental students are assigned a critical appraisal of information, they come back to one of us on the staff with the complaint, "But, Doctor, how am I going to tell who is an authority?" Usually they are referred back to the instructions in a small manual* which has been supplied to them. I said "manual" not textbook. And I will repeat some of the statement in this manual to you this morning. I don't think it will be quite competitive to the statements by Dr. Wallace, but maybe it will bolster some of them-at least I hope.

This manual says,

"Possibly the first questions to be asked, in the evaluation of information, deal with the publication in which the article is printed. One asks, is the journal published by a critical, scientific, professional society? Is it the publication of an uncritical trade organization? The material in some highly scientific journals is submitted to the rigors of a board of censors; while some journals are compelled to accept any material that is available in order to put out a publication.

"The second question concerns the writer of the article. Has his record in the past demonstrated that he has a careful, accurate, scientific attitude?

"Then one asks about the setting in which the writer is working. Does he belong to the staff of a hospital, a foundation, a research clinic or a university, or does he write from the background of isolated private practice? Is he working with a group that has available ample equipment and clinical library and consultative services, or is he working with a mediocre group that is inclined toward hasty conclusions and frequent reporting of them?",

Then continues the manual-

"Study of the statement of the writer provides the final criterion of evaluation. The introduction of the article, alone, may indicate that it reports painstaking research, careful observations or clinical investigations. If the writer wishes to have others accept his statement as truth, he must substantiate his conclusions by acceptable scientific data. His conclusions must be stated with an open mind at all times and be made critically without prejudice. It seems impossible to seek truth once one has acquired a biased opinion.

"If the writer is reporting research investigations, one may ask, has he set up his laboratory or clinical situation to exclude modifying factors and has he provided satisfactory controls? Any article reporting conclusions based on experimental evidence should submit enough data in order that the reader may be able to check results. Usually, one may expect summarizing charts or tables and at least enough of the mathematical procedure employed to enable the reader to determine how the conclusions were derived and to permit the application of statistical tests, if one wishes, to check the validity of these conclusions."' cessed.

*Report writing in dentistry (Ann Arbor, University of Michigan, 1946.) 26 p. pro- 
Then our little manual continues-

"The subjects utilized for the research should be described accurately as well as the conditions under which the experiment was performed or the observations made. No essential portion of the experiment should be left to the reader's imagination. Unless this essential information is supplied, faulty technics may go undetected.

"The reader must not be impressed unduly by 'Iarge sample' experiments. A large group of subjects with mixed characteristies may supply information of less value than that from a small group of subjects more carefully selected. It always is well to question, is the sample significant? On the other hand, it is not fair to ignore data obtained from well-planned studies utilizing small samples, since these studies can supply very reliable information. It is frequently of value to ask, could other conclusions be drawn with equal validity from the data submitted, or could it be that chance, alone, is operating? Human beings are prone to credit a cause-and-effect relationship to coincidental findings-- 'post hoc, ergo propter hoc,' said the Romans!' And perhaps the Romans had a thought.

To get back to this Caries Control Training Program, something of this attitude, too, I have hoped might be interjected into this week's activities, and I was pleased when Dr. Wallace brought along his outline for the evaluation of information. At least we should like to tackle our job with a productive attitude. That is why Dr. Marguerite Hall and her entire staff of vital statisticians will serve you people as consultants during this period. They will be added to some of the dentists in this group, who I know have a very excellent background in statistical treatment. That is why, too, Miss Hilda Rankin and an augmented staff of librarians are available in the School of Dentistry to supply you promptly with the documented evidence submitted by our imported faculty during the week, and any other evidence which you wish to diseover on your own initiatives.

Now, in order to present some further details that may be helpful to you during the remainder of the week, I shall have to report some of our early planning. Sometime last January a letter went out to each member of the advisory group to settle the theme for this week of study. Members of the group were given a choice of two themes, (1) the assembly of complete dental health data for planning an adequate children's dental program and its analysis at the state level and (2) the evaluation of "what-is-fact" in oral health information.

For a study of the complete problem that dentists would meet if they were to set out seriously to provide adequate dental health care for all of the children of a designated state, it was suggested to this Planning Committee that seven areas of information, of data or facts, would have to be gathered and explored. The first one was the adoption, the setting-up of standards of oral health care for children. These standards, the operations that we are going to perform for children that are adequate for their health, would have to be defined carefully at the beginning. The second area was to aseertain the population facts that were required. The third area of that experience would be the study of the 
economic status of the designated state. And the fourth area to be explored would be to estimate by age groups the defined oral health needs of children either on the basis of their accumulated needs or on the basis of their incremental yearly needs. And the fifth area was a very complete census of all of the personnel of a state, of all who contribute to a children's dental program. And the sixth area was to prepare an estimate of the productivity of the state's dental personnel. And then, finally, the seventh area that we planned to explore, or suggested that might be explored, was the blocks to dental care. The blocks to dental care may be psychologic, economic, and even professional. Following this fact-finding excursion and accumulation of data, it was planned that a number of the pertinent problems in the field of dental economies would be proposed and then would be solved. That was one choice submitted for a Workshop.

Then, for the other choice, the "What-is-fact" Program, it was postulated, logically should receive priority since any planning to provide a complete dental health program for the children of a state should be preceded by the orderly evaluation of scientific information. Such an order of procedure would appear pertinent, at least, before clinical services finally are decided or dental health education programs launched to remove these psychologic blocks to dental care, that I just mentioned, or to educate people in preventive technics. It was stated further that four fields of "what-is-fact" in dental health should be evaluated thoroughly: (1) dental caries control, (2) maintenance of the health of gingival and supporting tissues, (3) occlusion and the interception of malocclusion, and (4) oral and systemic interrelationships. The vote of the planning group was registered almost unanimously for the "What-is-fact" conference and the first choice of areas of evaluation went to "caries control." As you may have guessed, should you react enthusiastically to the present discussion, we still have three other areas of dental health information to evaluate at later dates, then we shall be ready probably to start all over and return to dental caries control.

The planning for this week then proceeded as it was outlined in the preliminary letter. At that time it was decided that the inservice training course technic would be employed to appraise critically the present status of the various control measures now being made available by research and clinical observation. Lectures would be presented during the morning periods by sixteen wellknown research workers in the fields of caries control, oral bacteriology, oral histopathology, biochemistry, nutrition, and periodontology and the afternoon sessions would be devoted to small group discussions and evaluations of six areas of caries control. As Dr. Wallace stated, we did not quite correlate with his very logical classification of areas of discussion. If you will consult the programs you will note that there are six committees to evaluate (1) the mechanism of the caries process; (2) relationship of systemic conditions to the caries process; (3) the effectiveness of prophylaxis, toothbrushing, chewing gum, dentifrices and mouthwashes, and the things which ean be done at home by way of mouth hygiene in the control of caries; (4) the utilization of fluorides and silver salts 
in the control of earies; (5) the relationship of vitamin and mineral ingestion to dental caries; and (6) the contribution of different types of diet to earies control.

Each evaluating group was to work under a designated leader with the assistance of research, statistical and library consultants, and also with the assistance of duplicated bibliographies of references which have been cited by the speakers. Also, along with these lists of references, so that you can subject the documented statements to the acid test, will be a list of questions, which it seemed to a group of us, should be raised and should be answered before a set of critical conclusions were written for presentation in the final session Saturday, September 13. That much already has been done by the planning group to start off the Evaluating Committees on Tuesday afternoon.

The activity of the six evaluating groups will determine the outcome of this conference-whether it is a success, whether it is mediocre, or whether it is just a plain failure. The planning group hoped that such an organized program would result, by the end of the week, in a brief statement of conclusions about (1) the factors that are essential for the caries process and (2) the scientific value of each control measure available. It was hoped, further, that these conclusions would be reached by a courteous, unbiased but extremely critical discussion of the validity of the data submitted.

In order to keep diseussion on an objective, unemotional plane, the entire statisties division of the School of Public Health was drafted to reinforce the statistical training of some of our dentists, the talent that we already have in this group, so that you could turn to these technical people any time that you wished, have them apply certain statistieal tests, and tell you whether the results were valid. It was hoped, finally, that the participants would shed all of their traditional respect for authority, coldly dissect research conclusions for their accuracy and unceremoniously state that more or better research is necessary when a question cannot be decided by the merits of existing data. Furthermore, as I have said, all of us hoped that you would enjoy the experience or we wouldn't have worked so hard to provide it for you.

Some features have been added unknown to the planning group, for example, there is to be a subseription dinner.

The faculty and group leaders already have held one session in which they were "briefed" Sunday evening. The lectures by our imported faculty all will be given in this auditorium. All of the activities of the evaluating groups are scheduled in the School of Dentistry and Kellogg Institute where seminar rooms will be available, and I hope cool, and where a well-stocked and well-appointed dental library is available, housing the data which, I think, the essayists at this meeting will submit.

That appears to be, perhaps a bit sketchily, your week-long program. I hope most sineerely, speaking as a very, very recent grandparent, that the results of this program will demonstrate consistently that a dental fact must become sufficiently grown up and strong enough, lustily to stand on its own two feet before it starts out in the world for acceptance as the basis for dental practice or for the education of the public. 
Mr. Charles F. Kettering of General Motors' Research fame, whose pithy sayings I usually read and usually enjoy, once stated, "Before embarking on a new experiment it is well to have a rather definite notion about where you are going; otherwise you never will know when you get there." Adopting Mr. Kettering's thesis as a principle of action, I have tried this morning to draw a picture for you of where you are going this week. Such an effort appeared, to me, to be just common courtesy. It would seem that if one does not like what is about to hit him, it would be more comfortable to have an opportunity to withdraw early.

\section{(Meeting adjourned for luncheon)}

\section{Monday, September 8 \\ Afternoon Session}

DR. EASLICK.-This morning we attempted rather seriously, in many ways, to provide you with an orientation experience to the week's program. Now that you have completed this freshman exa successfully and purchased your notebooks, you are expected to tackle, with a truly seientific approach, some of the problems involved in the control of dental caries.

The first group of lectures to be presented in this auditorium in the pursuit of fact deals with the process of caries, the mechanism of caries. It seemed sensible to the Planning Committee to review that which is known scientifically about the process of caries before an evaluation of control technics is attempted. Possibly, the Committee surmised, some of the conflict of opinion and many misconceptions and a few dead-end paths could be avoided if everyone were exposed to a clear-cut concept of the factors essential for caries and the avenues, therefore, for interference with each one of these factors.

Probably, the Committee continued in its reasoning, the initial step in such a review of the process of caries should be a statement of the information to be derived from the embryology, the histology, and the physiology of the hard tissues most directly concerned in the caries process, i.e., the enamel and dentin of human teeth. Our neighboring State of Ohio, with which the pioneers of the State of Michigan, back in 1835, fought a bloodless war and lost Toledo, supplies the first afternoon speaker. This speaker undoubtedly worked the hardest of any of our imported faculty last night at the briefing meeting; so $I$ know that he is well prepared today.

Dr. Samuel W. Chase, who is Professor of Histology and Embryology in the School of Dentistry of Western Reserve University, Cleveland, accepted as his forty-five-minute assignment " The Development, Histology and Physiology of Enamel and Dentin-Their Significance to the Caries Process." 